Fecha de recepción: mayo 2021 Fecha de aceptación: junio 2021 Versión final: julio 2021

\section{Aproximaciones metodológicas en la nueva normalidad para la investigación cualitativa en las áreas del diseño}

Zennia B. Ruiz Rodríguez ${ }^{(1)}$, Erika Rogel Villalba ${ }^{(2)}$

y Leonardo Moreno Toledano ${ }^{(3)}$

\begin{abstract}
Resumen: Es eminente, que la pandemia generada por el COVID-19 ha marcado un precedente en la vida diaria de todos los seres humanos y las universidades, no han sido la excepción. El objetivo de esta propuesta, es presentar algunos métodos y técnicas de acopio de información cualitativa, sobre el acopio de información centrada en el usuario, que pueden ser útiles para la nueva normalidad, en las áreas de la investigación del diseño. La metodología se desarrolló a través del uso de pruebas y sondeos culturales, aplicado al tema de violencia de género desde una perspectiva social de la mujer y la reproducción social de la vida cotidiana. Las conclusiones, son sobre la interpretación del material recolectado.
\end{abstract}

Palabras clave: Investigación Cualitativa - Sondeos Culturales - Historias de Vida - Diseño - Violencia de Género.

[Resúmenes en inglés y portugués en la página 187]

(1) Estudiante del Doctorado en Diseño por la Universidad Autónoma de Ciudad Juárez (UACJ). Cuerpo Académico: Diseño, Usuario y Entorno. Integrante del proyecto Gender Design STEAM en la Universidad Carleton Canadá: Rethinking Design through against gender violence.

(2) Profesora por la Universidad Autónoma de Ciudad Juárez (UACJ). Miembro del Sistema Nacional de Investigadores SNI nivel 1. Responsable del proyecto Gender Design STEAM en la Universidad Carleton Canadá. Cuerpo Académico: Diseño, Usuario y Entorno.

(3) Coordinador de la Maestría en Estudios y Procesos Creativos en Arte y Diseño UACJ. Líder del Cuerpo Académico: Diseño, Usuario y Entorno. Miembro del SNI. Co-responsable del proyecto Gender Design STEAM en la Universidad Carleton Canadá. 


\section{Introducción}

Es eminente, que la contingencia sanitaria causada por el coronavirus sars cov-2 (COVID-19), ha marcado un precedente en la vida diaria de todos los seres humanos, afectando actividades cotidianas como educación, trabajo, recreación y ambiente familiar, solo por mencionar algunas. Las universidades, no han sido la excepción a estas dificultades, frente a la pandemia, las consecuencias y costos han impactado a toda la comunidad, administrativos, docentes y alumnos.

En el Informe de Políticas de las Naciones Unidas, se menciona que:

Los ingentes esfuerzos realizados en poco tiempo para responder a los impactos en los sistemas educativos nos recuerdan que el cambio es posible. Es necesario aprovechar la oportunidad para encontrar nuevas formas de afrontar la crisis en materia de aprendizaje y aportar un conjunto de soluciones que antes se consideraban difíciles o imposibles de poner en práctica (2020, p.4).

En el área de investigación, estudiantes y docentes de pregrado y posgrado y también se han visto afectados, ya que hemos pasado de un confinamiento inicial esperado entre treinta días a tres meses, a poco más de un año y sin indicios aún, de un próximo regreso. Debido a ello, algunas investigaciones han tenido que ser postergadas y en ocasiones canceladas, o bien ha sido necesario cambiar los grupos de estudio, a causa de la imposibilidad de salir a campo o acercarse a las personas, ante las disposiciones de confinamiento. Sin embargo, los fenómenos y problemáticas a estudiar, continúan siendo necesarias, e inclusive, en algunos casos, se han agravado. Es por ello, que, en ésta nueva normalidad, es preponderante buscar nuevos mecanismos de investigación, validación y apoyo, que nos permitan abordar y dar respuesta a lo anterior, principalmente, aprovechando las tecnologías actuales.

\section{El diseño y la investigación}

El diseño es toda aquella actividad creada y desarrollada para satisfacer las necesidades del hombre, en algunos casos, se le ha considerado la ciencia de lo artificial (Simon, 1996). Ciertamente, el diseño es algo mas que solo estética y creatividad, es una disciplina que busca resolver problemas por medio de procesos y métodos que le permitan establecer y evaluar objetivos claros, para poder desarrollarlos a través de una planeación estratégica medible. Por tanto, es necesario el uso de métodos rigurosos que permitan un adecuado levantamiento de datos y evaluaciones de las propuestas generadas, ya que la investigación, es un concepto clave en el mundo y en las sociedades modernas, por lo que están fuertemente vinculados, como Margolin (2003) comenta en su libro, Las Políticas de lo artificial: "el pensamiento nuevo surge en gran medida de la participación en el pensamiento de otros, más que de la invención de teorías y argumentos en completo aislamiento" (p.22). 
En el desarrollo de un proceso de investigación, se recoge información, pero no con la finalidad de obtener un reconocimiento, sino para contar con materia prima, que sirva como punto de partida, para observar, reflexionar y generar nuevas investigaciones. No debemos olvidar reconocer la importancia de la obtención de la información, en donde lo realmente valioso es la utilización que se hace de ella. Asimismo, las universidades buscan ser reconocidas, no para llenar a sus estudiantes de información, sino para ser productoras y creadoras de nuevo conocimiento. La investigación es un proceso que, mediante la aplicación sistemática de información, procura obtener datos relevantes y fidedignos, para extender, verificar, corregir o aplicar el conocimiento.

En este sentido, se podría establecer que la investigación se puede dar en cualquier lugar, y que su fin es indagar, buscar, acopiar y observar, con el propósito de obtener generalizaciones que permitan extender, corregir o verificar el conocimiento, y que este aporte al desarrollo de la teoría o bien de la práctica de diversos sucesos o fenómenos. Es por ello, que no esta separada la teoría de la práctica, como tampoco debemos separar la investigación del diseño.

\section{La complejidad de las problemáticas en diseño}

Cuando hablamos de la disciplina o de la ciencia del diseño, nos referimos al diseño responsable, sostenible y sustentable, con impacto cultural, aquel que estará centrado en las necesidades del usuario y del entorno, del impacto económico y político, mismo que requiriere de una mayor robustez en su proceso y diseño metodológico, para que se valide cada etapa de desarrollo. Por ende, este tipo de diseño necesita de un soporte teórico, en el que la investigación se encuentre centrada en las necesidades del usuario, asimismo, debe ser responsable del impacto en su entorno, considerando las causas y factores que atañen alrededor de un problema complejo, entendido este, como un problema en el que se desarrollan relaciones diversas entre un gran número de individuos y en el que participan diversas variables, usualmente de disciplinas heterogéneas. En este tipo de problemas, los métodos son definidos desde las necesidades de la problemática; entre más conocimiento se tenga del problema, este será más claro, y será más fácil definir la estrategia y ruta de la investigación. Sin embargo, desde esta perspectiva deberemos considerar que las problemáticas complejas que el diseño enfrenta y presentan aspectos multifactoriales que requieren de nuevas formas de abordar los problemas desde el diseño.

En palabras de Morín (2005):

La complejidad es la unión de los procesos de simplificación, que implican selección, jerarquización, separación, reducción con los otros contra procesos que implican la comunicación, la articulación de aquello que esta disociado y distinguido; y es el escapar de la alternativa entre el pensamiento reductor que no ve más que los elementos y el pensamiento globalista que no ve más que el todo (p.144). 
De igual forma, Morales, A. \& Cabrera, V. (2017) establecen que:

[...] desde la visión compleja se considera que los fenómenos contienen una fuerte estructura interrelacional, que implica una actividad cognitiva interdisciplinar. La elección de componentes y la omisión arbitraria de otros simplemente es inconcebible e insostenible, pues el conocimiento organismico integral, de naturaleza circular, es el que propicia aproximaciones a la complexidad, por ello se asume que el pensamiento complejo se presenta como la opción más viable (p. 21).

Finalmente, Moreno, L. \& Rogel, E. Consideran que:

[...] el diseño es de una forma única para participar en la búsqueda de soluciones para ciertos temas complejos desde perspectivas y enfoques como la transdisciplinariedad. Esto pensó permite ampliar su alcance y oportunidades, tanto en la teoría como en la práctica, el diseño, ha pasado de ser una disciplina cuyo propósito fue el desarrollo de productos, espacios, objetos o comunicaciones a una disciplina capaz de comprender la complejidad del mundo actual y actuar con otros actores sociales (disciplinas, gobiernos, sociedad, etc.) en la búsqueda de soluciones para algunos de los problemas que enfrentan nuestras sociedades hoy (2018, p. 48).

\section{Métodos y procesos creativos para el diseño en tiempos de pandemia}

Como hemos mencionado con anterioridad, la contingencia sanitaria mundial, ha provocado un cambio en el paradigma en la enseñanza, así como también, un incremento en los fenómenos y problemas sociales, por lo que los estudiantes interesados en atender esta clase de eventos, se han visto con la necesidad de reestructurar sus estrategias para estudiar estas problemáticas sin poner en riesgo su salud. Entre los métodos para aproximarse a los usuarios y recopilar información significativa, encontramos especial interés en el método Design Against Crime (Diseño contra el crimen) y Cultural Probes (pruebas culturales) ya que brindan una oportunidad de acercamiento cualitativo desde el diseño y la innovación para el cambio social, los cuales se explicarán a continuación:

\section{Pruebas o Sondeos Culturales}

Por otro lado, mediante el método Cultural Probes, (Pruebas o Sondeos Culturales), se estudia e investiga una comunidad, observando las conductas en períodos considerables de tiempo, se busca observar cambios socio-culturales, en procesos históricos y educativos, las funciones y los papeles de los miembros de estos, esto puede hacerse durante 
un número indeterminado de sesiones, la información se recaba por medio de cámara fotográficas, lápiz, cuaderno y grabadora de voz, entre otros. Algunas maneras en que se busca recolectar información son:

Cuéntame una historia. El contar una historia tiene tres importantes puntos: es fácil asociarla a hechos de nuestra vida cotidiana, mantiene los conceptos abstractos, comúnmente es fácil expresar una idea, producto o es buena oportunidad para solamente desarrollar la creatividad. Las historias usan un gran rango de técnicas para convencer involucrar e inspirar gente, se usa un lenguaje simple y fácil de escribir. Es una buena herramienta de comunicación para compartir el conocimiento.

Percepción y Conciencia. El diseño tiene una alta participación en el significado de los productos que genera. El objetivo de este ejercicio, es explorar que problemas son los que ellos perciben en su localidad.

Impacto significativo en tu vida. A través de este ejercicio individual se trata de entender el punto de vista personal del usuario, definiendo previamente, que entienden por impacto significativo en relación con un listado de conceptos complejos y como los asociarían o representarían a través de su vida: cultura popular, prejuicios, mitos, estigmas, religión, identidad nacional, ídolo, corrupción, policía, gobierno, educación, familia, economía, etc.

Collage. El papel de la comunicación visual no termina con su manufactura, o su distribución. El propósito estará terminado cuando estos generen una influencia en la gente. A través de este ejercicio, se pretende que los investigadores observen la influencia que generan los medios locales de información.

Cómo el significado es formado. Las imágenes están todo el tiempo a nuestro al rededor y la habilidad de crear o bien interpretar su significado es una habilidad vital que el diseñador deberá de poseer. El significado de cada signo, icono, imagen o símbolo, afecta dependiendo quien lo este recibiendo todas las cosas significan, pero no todas comunican. a través de trabajos individuales se investiga el significado e influencia de la información generada

\section{Desarrollo del Caso de estudio: Intervención de diversas estrategias para intervenir la violencia de género en Ciudad Juárez}

Ya expuestos los métodos e instrumentos para el diseño y el cambio social, se seleccionó la estrategia de Cultural Probes, para un primer acercamiento, con la intención de buscar e identificar singularidades en el proceso de sanación frente a una situación de violencia de género, para recopilar dicha información se utilizó el instrumento Tell me your story a una muestra de cinco mujeres de entre 50 a 60 años de edad que fueron víctimas y sobrevivientes de violencia en el matrimonio, esto, con el propósito de conocer su proceso de resiliencia y detectar que fue lo que influyó para hacerlas salir del círculo de violencia al 
que estaban sometidas Esto sirvió como estrategia para que el estudiante no invadiera la vida privada de las usuarias, y logró que relataran su historia de vida a través de un cuento, lo que permitió presentar el testimonio de vida con fluidez y generar una catarsis al momento de escribir y usar imágenes representativas.

\section{Propuesta modelo Tell me your story}

Aunque el modelo de tell me your story puede ser usado de diversas formas, el expuesto a continuación consta de siete etapas: inicio, desarrollo, crisis, catástrofe, epifanía, resolución y epílogo. Cada fase expone términos narrativos que sirven como guía para relatar la historia, los cuales son:

- Inicio: mencionar el origen del personaje, el contexto donde creció y las características de su familia.

- Desarrollo: relata como el personaje conoce a su pareja (agresor), dónde se conocieron y cómo era su relación en el comienzo.

- Crisis: describe el primer conflicto que tuvo el personaje con su pareja

- Catástrofe: menciona el último conflicto que tuvo el personaje con su pareja

- Epifanía: narra como se resolvió el problema, qué o quién la ayudó a salir del conflicto y romper el ciclo de violencia.

- Resolución: cómo es la vida del personaje después de alejarse o "vencer" al agresor.

- Epílogo: relata cómo es la vida del personaje actualmente, y ¿qué haría el narrador para ayudar al personaje a sentirse mejor?

Los resultados de analizaron conforme a los elementos descritos en la tabla, una vez dado el material a las usuarias, se les dio un tiempo de una semana para redactar su historia, las usuarias usaron diferentes estrategias de expresión para contar el relato, algunas utilizaron el apoyo visual de recortes de revista y otras imágenes de internet. Cabe mencionar, que hubo dificultades debido a que las instrucciones se dieron vía internet, por lo que el mensaje no resulto claro, asimismo, en ocasiones, por el contexto de vida actual en el que estamos inmersos, el cuidado de los niños, el trabajo, etc., las mujeres se olvidaban del ejercicio o lo posponían, lo que hizo complicado la obtención de resultados ya que no podíamos visitar o convocar directamente a las participantes. Por lo que fue necesario contemplar todos los factores externos que puedan surgir y resolver los problemas de comunicación sobre la marcha. Los resultados fueron los siguientes: 


\begin{tabular}{|c|c|c|c|}
\hline \multicolumn{4}{|c|}{$\begin{array}{l}\text { Cuéntame tu historia: Usuaria } \mathrm{l} \text {, Mirna } \mathrm{M} \text {. } \\
\begin{array}{c}\text { Descripción } \\
\text { La usuaria relató su historia y experiencia personal, utilizando imágenes }\end{array} \\
\text { pictóricas y caricaturizadas de internet,(véase, figura } 1 \text { ). }\end{array}$} \\
\hline inicio & Desarrollo & crisis & catástrofe \\
\hline $\begin{array}{l}\text { Relata a una mujer de } 29 \text { años } \\
\text { profe sionista y madre soltera, } \\
\text { con estudios en sociologia e } \\
\text { inmigrante en los Estados } \\
\text { Unidos de América. }\end{array}$ & $\begin{array}{l}\text { Relata que conoció a su } \\
\text { pareja en una reunión de } \\
\text { masaje, menciona que es } \\
\text { padre soltero. }\end{array}$ & $\begin{array}{l}\text { Describe diferentes tipos } \\
\text { de violencia manifiesta } \\
\text { en el hogar (emocional, } \\
\text { económica, verbal)y } \\
\text { amenazas para } \\
\text { deportarla. }\end{array}$ & $\begin{array}{l}\text { El último conflicto fue } \\
\text { una pelea verbal y una } \\
\text { amenaza cumplida, por } \\
\text { lo que fue deportada } \\
\text { como ilegal en el pais. }\end{array}$ \\
\hline epifanía & Resolución & \multicolumn{2}{|c|}{ Epílogo } \\
\hline $\begin{array}{l}\text { la usuaria relata pedir ayuda } \\
\text { en centros de atención a } \\
\text { mujeres, y recibió tratamiento } \\
\text { psicológico y posteriormente } \\
\text { tramitó la visa para protección } \\
\text { de su familia. }\end{array}$ & $\begin{array}{l}\text { Menciona recibir ayuda } \\
\text { por parte del gobierno de } \\
\text { los Estados Unidos de } \\
\text { América y continuar su } \\
\text { vida junto a su familia en } \\
\text { un pais extranjero. }\end{array}$ & \multicolumn{2}{|c|}{$\begin{array}{l}\text { La usuaria describe estar conti muando con sus } \\
\text { estudios profesionales y encontrar un entorno de paz } \\
\text { y seguridad para su familia. }\end{array}$} \\
\hline
\end{tabular}

\section{Cuéntame tu historia}

En estas hojas siéntete libre de contarme una historia con imágenes u objetos que encuentres en tu casa, sigue la secuencia que se te pide para desarrollar el relato, puedes hacerlo del número de páginas que tu quiera.

Inicio: Cuéntame sobre el origen del personaje, ¿dónde creció?, ‘cómo es su familia?, ¿qué le gusta y qué le véase, figura 2).jisgusta?

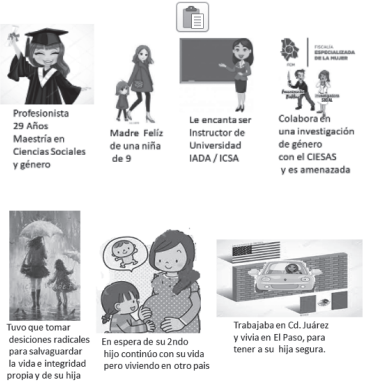

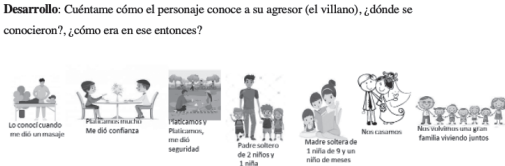

Crisis: Cuéntame cómo el personaje tiene el primer conflicto con el villano $ə$ qué sucedió? ¿cómo hizo sentir a tu personaje? \}ómo fue su vida a partir de ese momento?

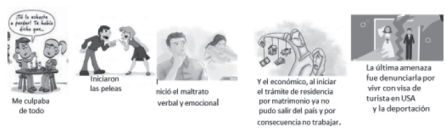

Catástrofe: Cuéntame oómo fue el último conflicto con el villano, qué hizo el personaje, cómo se sentía

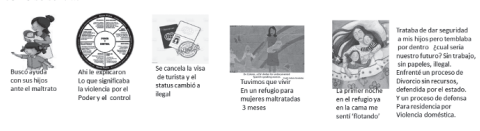

Figura 1: Imagen del relato, usuaria 1(Ruiz, 2020). 


\begin{tabular}{|c|c|c|c|}
\hline \multicolumn{4}{|c|}{ Cuéntame tu historia: Usuaria 2, Gloria, $\mathrm{R}$. } \\
\hline $\begin{array}{c}\text { Descripción } \\
\text { inicio }\end{array}$ & \multicolumn{3}{|c|}{$\begin{array}{l}\text { La usuaria relató su historia y experiencia personal en tercera persona, } \\
\text { utilizó recortes de revista para ilustrar sus recuerdos, (véase, figura 2). } \\
\text { Desarrollo crisis }\end{array}$} \\
\hline $\begin{array}{l}\text { Relata a una mujer proveniente de } \\
\text { una familia de obreros, en un sector } \\
\text { socioeconómico bajo, donde la } \\
\text { violencia era común entre los } \\
\text { miembros de la familia. } \\
\text { La mujer se desarrolla } \\
\text { académicamente y se independiza. }\end{array}$ & $\begin{array}{l}\text { Menciona estar estudiando } \\
\text { en la universidad cuando } \\
\text { conoció a su pareja en una } \\
\text { plaza, relata que el varón era } \\
\text { detallista y romántico en un } \\
\text { principio. }\end{array}$ & $\begin{array}{l}\text { Describe } \\
\text { diferentes tipos de } \\
\text { violencia, desde el } \\
\text { control, } \\
\text { psicológica, acoso } \\
\text { y muestras de } \\
\text { machismo. }\end{array}$ & $\begin{array}{l}\text { E1 último conflicto } \\
\text { ocurre años después, } \\
\text { después de formar una } \\
\text { familia juntos, cuando } \\
\text { la pareja hace } \\
\text { comentarios de critica } \\
\text { y culpa. }\end{array}$ \\
\hline epifanía & Resolución & & epilogo \\
\hline $\begin{array}{l}\text { La usuaria relata tomar la decisión } \\
\text { de separación, por el bien de su } \\
\text { salud y estabilidad emocional y el } \\
\text { de sus hijas. Pone el limite y pide a } \\
\text { su pareja alejarse de su vida. }\end{array}$ & $\begin{array}{l}\text { Menciona sentirse feliz y libre } \\
\text { de la relación, recibe ayuda de } \\
\text { la familia y amistades, pero } \\
\text { principalmente de la religión } \\
\text { cristiana en momentos de crisis. }\end{array}$ & $\begin{array}{l}\text { La usuaria descri } \\
\text { docente, y en esta } \\
\text { menciona que si } \\
\text { valorarse a si mis } \\
\text { sentirse segura y }\end{array}$ & $\begin{array}{l}\text { be estar laborando como } \\
\text { bilidad con su familia, } \\
\text { pudiera ayudaria a } \\
\text { ma en el pasado y } \\
\text { amada por ella misma. }\end{array}$ \\
\hline
\end{tabular}

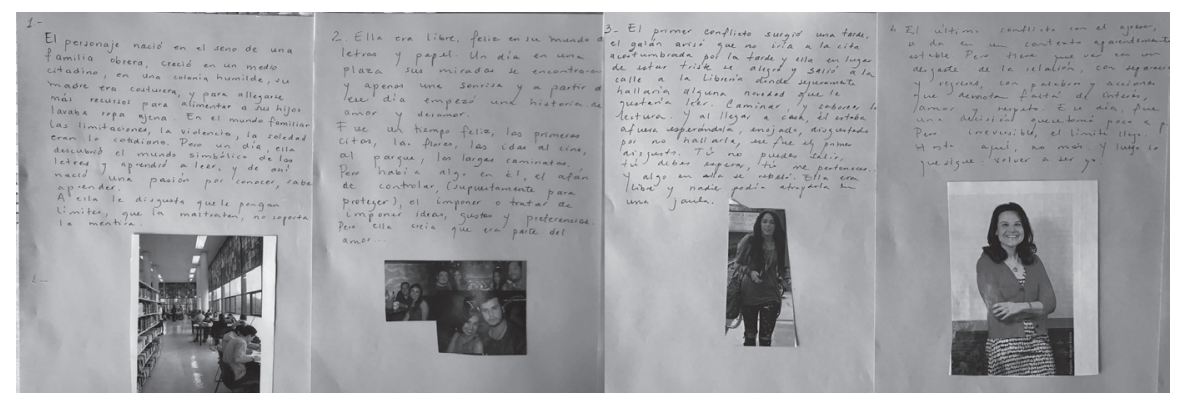

Figura 2: fotografías del relato, usuaria 2 (Ruiz, 2020).

\begin{tabular}{|c|c|c|c|}
\hline \multicolumn{4}{|c|}{ Cuéntame tu historia: Usuaria 3, Lilian, B } \\
\hline Descripción & \multicolumn{3}{|c|}{$\begin{array}{c}\text { La usuaria relató su historia de vida a manera de cuento con personajes } \\
\text { animales. (véase, figura 3). }\end{array}$} \\
\hline inticio & desarrollo & Crisis & catástrofe \\
\hline $\begin{array}{l}\text { Relata a una mujer con } \\
\text { estabilidad familiar y con } \\
\text { muchos miembros, sin } \\
\text { embargo, era testigo de } \\
\text { maltrato emocional y } \\
\text { fisico a sus hermanos por } \\
\text { parte de los padres. }\end{array}$ & $\begin{array}{l}\text { La usuaria conoce a su } \\
\text { pareja en el trabajo, } \\
\text { quien muestra interés a } \\
\text { través de regalos, y } \\
\text { acciones románticas, } \\
\text { con el tiempo se casan } \\
\text { y forman una familia. }\end{array}$ & $\begin{array}{l}\text { El primer conflicto ocurre el dia } \\
\text { de su boda cuando la pareja } \\
\text { abandona a la usuaria a } \\
\text { consecuencia de una pelea, } \\
\text { posteriormente se manifestaron } \\
\text { situaciones de control y } \\
\text { aislamiento sobre la usuaria. }\end{array}$ & $\begin{array}{l}\text { E1 último conflicto } \\
\text { fueron situaciones que } \\
\text { fueron escalando, hasta } \\
\text { llegar al engaño y el } \\
\text { control sobre la usuaria } \\
\text { y sus hijos. }\end{array}$ \\
\hline epifania & resolución & \multicolumn{2}{|c|}{ Epílogo } \\
\hline $\begin{array}{l}\text { la usuaria tener un } \\
\text { momento de revelación } \\
\text { gracias a un momento de } \\
\text { acercamiento al } \\
\text { cristianismo. }\end{array}$ & $\begin{array}{l}\text { La usuaria relata que } \\
\text { ahora es libre de } \\
\text { ataduras y a pesar de } \\
\text { los problemas es feliz }\end{array}$ & \multicolumn{2}{|c|}{$\begin{array}{l}\text { La usuaria menciona que sigue laborando, y educa a sus } \\
\text { hijos sola pero que continúa guiando a su familia a los } \\
\text { caminos del cristianismo. }\end{array}$} \\
\hline
\end{tabular}




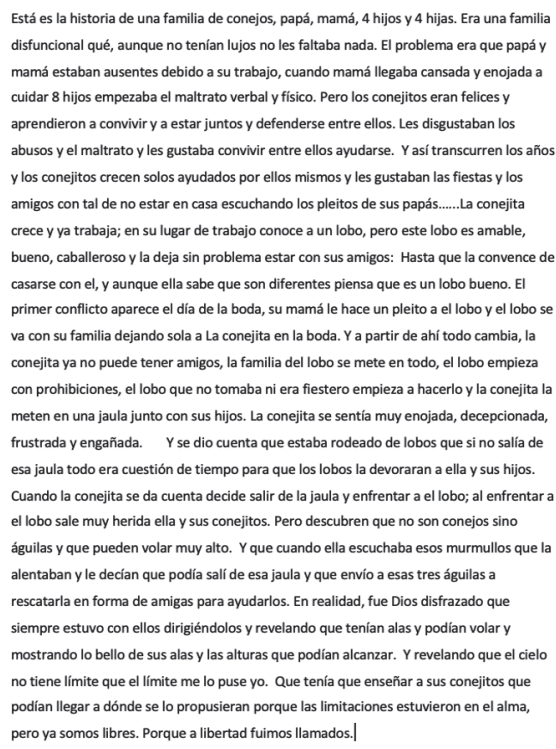

Figura 3: Foto captura, cuento, usuaria 3 (Ruiz, 2020).

\section{Resultados}

Al finalizar el ejercicio se les hizo una corta entrevista desde su experiencia, las preguntas fueron: ¿Recuerdas que campañas o proyectos se realizaban para la prevención o información sobre violencia de pareja? Las cuatro integrantes mencionaron no recordar campañas sobre el tema, una de ellas, menciona que lo común era ver proyectos enfocados a el cuidado y prevención de enfermedades de transmisión sexual y embarazos no deseados, otra, quien tenía información más detallada sobre violencia de género, relató que los proyectos que recuerda eran los realizados dentro del instituto de ICSA de UACJ. La siguiente pregunta fue, ¿Consideras que las campañas realizadas son eficaces para tratar el problema de violencia a las mujeres? Las cinco mencionaron que son eficaces medianamente, porque cumplen con el objetivo de informar, pero no de persuadir o convencer a las mujeres que viven en una situación de violencia, también mencionaron que dichas campañas no instruyen a las mujeres a reaccionar y en su mayoría no se enfocan a cambiar la postura del agresor. La última pregunta fue, ¿Qué propondrían ellas para disminuir, y prevenir la violencia de pareja? las cinco mujeres sobrevivientes mencionaron que propondrían un programa educativo que enseñe a los niños a detectar el abuso e informar o denunciarlo, 
donde se aplique un programa integral sobre sexualidad, educando a los adolescentes a responsabilizarse por su acciones y cambiar la postura que existe sobre el macho, sin que sea tema censurado o tabú en las instituciones educativas. A la par reeducar a las familias sobre las consecuencias de la violencia y evitar su normalización.

\section{Conclusiones}

La pandemia generada por el COVID - 19 constituyó un parteaguas en muchos sentidos, tendremos que acostumbrarnos a que las cosas no volverán a ser como antes, en muchos de los aspectos que nos rodean. Como investigadores, deberemos de aprender nuevos métodos y procesos para interactuar e intervenir con los usuarios. Si bien es cierto, hemos aprendido bastante de otras disciplinas al tratar de aplicar sus métodos y metodologías adaptándolas a nuestras necesidades. Hoy, estas técnicas de acopio de información deberán considerar una aproximación e interpretación mas detallada. El caso de estudio que aquí se presentó, muestra una serie de materiales, mismos que requieren de un análisis mas minucioso, las diversas interpretaciones que de aquí se desprendan determinarán y recaerán sobre la propuesta final que el diseñador genere.

Los métodos de acopio de información que presenta el método Cultural Probes, pudieran, a simple vista, considerarse fáciles de entender y desarrollar; sin embargo, se debe establecer la empatía y reflexionar sobre los obstáculos de una persona al exponer su intimidad a un extraño. Además, el reto no solo fue que las integrantes del grupo generaran esta confianza a través de una participación lúdica. El mayor reto fue y es la interpretación que de ello emane, desde lo micro hasta lo macro, todas aquellas consideraciones que pudieran dar cuenta, son importantes y en ello radica la complejidad de la investigación y la interpretación del material recabado.

Trabajar el Diseño desde la perspectiva y necesidades del usuario, no es una tarea sencilla, una vez determinada la propuesta de diseño, será necesario cubrir diversos aspectos. La tecnología ha venido a rediseñar los procesos de acopio de información de los métodos Sondeos y Pruebas Culturales, ya que el trabajo de campo, la información que se recababa cara a cara, hoy ya no es posible. Sin embargo, surge un área de oportunidad, para aprender evaluar y readaptar nuestras técnicas de acopio de datos.

\section{Listado de Referencia Bibliográfica}

Informe de Políticas: La Educación durante la COVID-19 y Después de ella (2020). Naciones Unidas. Recuperado de: https://www.un.org/sites/un2.un.org/files/policy_brief_-_education_during_covid-19_and_beyond_spanish.pdf

Margolin, V. (2005) las Políticas de lo Artificial Ensayos y Estudios Sobre el Diseño. Editorial Designo ISBN I0: 968-5852-05-7 ISBN I3: 978-976-5852-05 -0 
Morales, A. \& Cabrera, V. (2017). Debate Teórico Metodológico sobre el Diseño Gráfico: de la linealidad a la complejidad. Intersticios Sociales El colegio de Jalisco núm. 13. Recuperado de: http://www.scielo.org.mx/pdf/ins/n13/2007-4964-ins-13-00002.pdf

Moreno, L. \& Rogel, E. (2018) Transdisciplinary Design: Tamed complexity through new collaboration. Strategic Design Research Journal 1 (11): 42-50 DOI 10.4313/sdrj.2018.111.07

Morin. E. (2005). "Introducción al pensamiento complejo", trad. de Marcelo Pakman, Barcelona, Gedisa, 2005, págs. 135-167. Recuperado de: https://estaciencia.files.wordpress. com/2017/04/epistemologc3adadelacomplejidad-morinedgar.pdf

Murphy, J. (2006) Cultural Probes: Understanding Users in Context. User Experience Magazine, 5(3), USA.

Simon, H. (1996). The Sciences of the artificial. Londres, MIT Press.

\begin{abstract}
It is eminent that the pandemic generated by COVID-19 has set a precedent in the daily lives of all human beings and universities have not been the exception. The objective of this proposal is to present some methods and techniques for the collection of qualitative information, on the collection of information focused on the user, which may be useful for the new normal, in the areas of design research. The methodology was developed through the use of cultural tests and surveys, applied to the issue of gender violence from a social perspective of women and the social reproduction of daily life. The conclusions are about the interpretation of the collected material.
\end{abstract}

Keywords: Qualitative Research - Cultural Probes - Storytelling - Design - Gender Violence.

Resumo: eminente que a pandemia gerada pelo COVID-19 estabeleceu um precedente na vida cotidiana de todos os seres humanos e as universidades não têm sido a exceção. $\mathrm{O}$ objetivo desta proposta é apresentar alguns métodos e técnicas de recolha de informação qualitativa, sobre a recolha de informação centrada no utilizador, que possam ser úteis para o novo normal, nas áreas de investigação em design. A metodologia foi desenvolvida por meio da utilização de testes e pesquisas culturais, aplicados à temática da violência de gênero na perspectiva social da mulher e da reprodução social do cotidiano. As conclusões referem-se à interpretação do material coletado.

Palavras chave: Pesquisa Qualitativa - Pesquisas Culturais - Histórias de Vida - Design Violência de Gênero.

[Las traducciones de los abstracts fueron supervisadas por el autor de cada artículo] 